\title{
Classification challenges in the field of eating disorders: can severe and enduring anorexia nervosa be better defined?
}

\author{
Phillipa Hay ${ }^{1 *}$ (D) and Stephen Touyz ${ }^{2}$
}

The field of eating disorders has notable problems of definition. For this year's Editorial we were stimulated to focus on this because it is both the year of pre-release of the 11th Edition of the International Classification of Diseases (ICD-11) [1] and PH was invited to present a paper on recovery in eating disorders. In doing so it became clear that there is little consensus for definitions for recovery [2] or more broadly other important clinical phases of anorexia nervosa. In particular, definitions of severe and/ or enduring illness are elusive and the concept of 'severe and enduring' is frequently misunderstood in terms of its conceptualisation [3, 4]. Such lack of definitional clarity is a problem for researchers, but even more so for clinicians who become confused, and most importantly for those living with the eating disorder.

Despite lack of definitional clarity, people with unremitting anorexia nervosa have very poor outcomes $[5,6]$ and there is little evidence based treatment for their care $[7,8]$. Only in the twenty-first century was an attempt made to incorporate recommendations for this group into clinical practice guidelines [8]. However, these guidelines referred to implicit clinical descriptors of longstanding illness with high morbidity, poor function and high health care use. In contrast diagnostic schemes such as the ICD-11 and Diagnostic and Statistical Manual of Mental Disorders Fifth edition (DSM-5) [9]) have explicit threshold criteria for persons to achieve a categorical diagnosis. The guidelines [8] did not apply or suggest specific criteria for severe and enduring anorexia nervosa - as there are none agreed - or discuss other severe and enduring eating disorders.

Clear definitions are very important. They are the reason the DSM-III in 1980 was universally popular to the point that copies had to be chained to desks to prevent their theft by students in the hospitals where we $(\mathrm{PH}$ and ST) then worked. The understanding of aetiology,

\footnotetext{
* Correspondence: p.hay@westernsydney.edu.au

${ }^{1}$ Translational Health Research Institute, School of Medicine, Western Sydney University, Sydney, Australia

Full list of author information is available at the end of the article
}

prognosis and the relationships between disorders rests on precise diagnosis, and valid and reliable diagnostic systems are necessary for meaningful communication between clinicians and researchers [10]. Let's examine 'severe and enduring' anorexia nervosa as it is conceptualised and then as it may be defined. We purport there are three components of severe and enduring anorexia nervosa: persistent unremitting symptoms, of long duration, and treatment resistance. First, the DSM-5 has definitions of severe for anorexia nervosa based on levels of body mass index (BMI; $\mathrm{kg} / \mathrm{m}^{2}$ ) which are cross-sectional [9]. Dakanalis et al. found these definitions of severity predict or converge with other aspects of anorexia nervosa illness severity and functional impact [11]. However, in the case of unrelenting illness these should be tempered as a person with a decade or more years of a BMI above the DSM- 5 severe range will have considerable morbidity from chronic starvation and longstanding illness - the latter term applied in the Touyz et al. randomised controlled trial of treatments for this group [7]. Second, considering duration, a systematic review reported that most who have written about this state in anorexia nervosa are referring to more than a few years of experiencing diagnostic level eating disorder symptoms with several previously failed treatment attempts [4]. The number of years of illness in the published literature ranges from 3 to 10, with a mode of 7 in this review [4]. In sum, the agreed lower limit of years appears to be three. The third key feature of treatment resistance is the most problematic to define. There are a diversity of approaches where individuals and/or their families have not responded to or do not wish to engage in first line therapies and also major differences across and often even within regions in how, when and what treatments patients are able to access.

As a trainee psychiatrist I (PH) recall a common question in our examinations was "The specialist approach to assessment of a person with treatment resistant disorder X". The answer always began with first, review the 
diagnostic formulation. Only after establishing that that the formulation is accurate, and the person has been offered and received all appropriate first line evidence based therapy is the term "treatment resistant" to be applied. Then the specialist will discuss second and third line therapies, including those often with higher risk, e.g., clozapine for schizophrenia or irreversible monoamine oxidase inhibitors for major depression. Finally, the "do no harm" or "comfort always" time honoured approach of clinical medicine - supportive care - may be offered.

However, we are reluctant to use the term "treatment resistant" in our field. It is perceived understandably as pejorative and blaming of the individual and those who care for them. It may seem to imply that as we have evidence based therapies, it's the person's fault if they "drop out", do not engage or otherwise are unresponsive. On the other hand, they may have not engaged because of poor health literacy on the part of the health care practitioner [12] who has e.g., told them when they sought help that they are not thin enough to have an eating disorder [13]. With the best of efforts treatment may yet fail if it is not person or family centred but rather 'Somebody Else's Roadmap' [14]. Treatment resistance is also poorly understood with no consensus on e.g., how many attempts at re-feeding or other treatments are enough before they cease. Yet, it is a common predicament for clinicians and people with the lived experience of anorexia nervosa.

Finally, it must be acknowledged that categorical systems are problematic in mental health where clinical features are often dimensional and boundaries are by necessity somewhat arbitrarily imposed. In consequence, diagnostic schemes such as the ICD-11 [1] allow more clinician judgment and flexibility than the DSM-5 [9] and may thus reduce the likelihood of harm from over rigid application of criteria in individual cases. As Wonderlich et al. [15] pointed out there is no strong empirical support for a clear demarcation separating people with longstanding anorexia nervosa from others. Thus, whilst we propose testable criteria (see Table 1) for 'severe and enduring anorexia nervosa' we would advise their judicious use by practitioners mindful of their limitations.

Table 1 Proposed criteria for "severe and enduring anorexia nervosa"

(1) a persistent state of dietary restriction, underweight, and overvaluation of weight/shape with

functional impairment

(2) duration of $>3$ years of anorexia nervosa; and

(3) exposure to at least two evidence based treatments appropriately delivered together with a

diagnostic assessment and formulation that incorporates an assessment of the person's eating

disorder health literacy and stage of change
The criteria we propose are based on (1) clinically significant functional impact i.e. impoverished and poor quality of life, with unrelenting symptoms, i.e. sustained dietary restriction leading to a persistent underweight state with weight/shape overvaluation and other eating disorder cognitions (2) duration of several years (minimum three) of anorexia nervosa, and (3) exposure to at least two evidence based treatments delivered by an appropriate clinician or treatment facility together with a diagnostic assessment and formulation that incorporates an assessment of the person's eating disorder health literacy with an assessment of the person's stage of change.

In conclusion, the Journal of Eating Disorders encourages submissions on any aspect of improving and testing current classifications and definitions in any domain relevant to the field, and including the neurosciences, in the spirit of the Research Domain Criteria approach [16]. We look forward to publishing research that will better define severe and enduring anorexia nervosa, recovery and other clinical states broadly in the field.

\section{Acknowledgements}

We thank the anonymous reviewers for their suggestions and improvements to this paper.

\section{Funding}

None.

Availability of data and materials Not applicable.

\section{Authors' contributions \\ $\mathrm{PH}$ and ST wrote the paper which was conceived by PH. Both authors read and approved the final manuscript}

\section{Ethics approval and consent to participate} Not applicable.

\section{Consent for publication}

Not applicable.

\section{Competing interests}

Stephen Touyz receives royalties from Hogrefe and Huber, Routledge and McGraw-Hill Publishers. He has also been the recipient of honoraria and travel and research grants from Shire Pharmaceuticals. He has chaired their Australian Binge Eating Disorder Advisory Board and has been the author of commissioned reports. All views expressed in these reports have been his own. Phillipa Hay receives sessional fees and lecture fees from the Australian Medical Council, Therapeutic Guidelines publication, and New South Wales Institute of Psychiatry and royalties from Hogrefe and Huber, McGraw Hill Education, and Blackwell Scientific Publications, and she has received research grants from the NHMRC and ARC. She is Deputy Chair of the National Eating Disorders Collaboration Steering Committee in Australia (2012-) and Member of the ICD-11Working Group for Eating Disorders (2012-) and was Chair Clinical Practice Guidelines Project Working Group (Eating Disorders) of RANZCP (2012-2015). She has prepared a report under contract for Shire Pharmaceuticals (July 2017) and conducts educational activities for Shire Pharmaceuticals. All views in this paper are her own.

\section{Publisher's Note}

Springer Nature remains neutral with regard to jurisdictional claims in published maps and institutional affiliations. 


\section{Author details}

${ }^{1}$ Translational Health Research Institute, School of Medicine, Western Sydney

University, Sydney, Australia. ${ }^{2}$ School of Psychology, The University of Sydney, Sydney, Australia.

Received: 15 July 2018 Accepted: 20 November 2018

Published online: 10 December 2018

\section{References}

1. World Health Organisation. International Classification of Diseases Eleventh Edition. 2018 https://icd.who.int. Downloaded 15 July 2018.

2. Khalsa SS, Portnoff LC, McCurdy-McKinnon D, Feusner JD. What happens after treatment? A systematic review of relapse, remission. and recovery in anorexia nervosa J Eat Disord. 2017;5(1):20.

3. Tierney S, Fox JR. Chronic anorexia nervosa: a Delphi study to explore practitioners' views. Int J Eat Disord. 2009;42:62-7.

4. Broomfield C, Stedal K, Touyz S, Rhodes P. Labeling and defining severe and enduring anorexia nervosa: a systematic review and critical analysis. Int J Eat Disord. 2017;50:611-23.

5. Keski-Rahkonen A, Mustelin L. 2016. Epidemiology of eating disorders in Europe: prevalence, incidence, comorbidity, course, consequences, and risk factors. Curr Opin Psychiatry. 2016;29(6):340-5.

6. Steinhausen HC. 2002. The outcome of anorexia nervosa in the 20th century. Am J Psychiatry. 2002;159(8):1284-93.

7. Touyz ST, Le Grange D, Lacey H, Hay P, Smith R, Maguire S, Bamford B, Pike KM, Crosby RD. Treating severe and enduring anorexia nervosa: a randomized controlled trial. Psychol Med. 2013 Dec;43(12):2501-11.

8. Hay P, Chinn D, Forbes D, Madden S, Newton R, Sugenor L, Touyz S, Ward W. Royal Australian and new Zealand College of Psychiatrists clinical practice guidelines for the treatment of eating disorders. Aust NZ J Psychiatry. 2014;48(11):977-1008.

9. American Psychiatric Association ( APA). Diagnostic and statistical manual of mental disorders- fifth edition. In: APA; 2013

10. Kendell RE. The role of diagnosis in psychiatry. London: Blakewell Scientific Publications; 1975

11. Dakanalis A, Timko CA, Colmegna F, Riva G, Clerici M. Evaluation of the DSM-5 severity ratings for anorexia nervosa in a clinical sample. Psychiatry Res. 2018;262:124-8.

12. Seah XY, Tham XC, Kamaruzaman NR, Yobas PK. Knowledge, attitudes and challenges of healthcare professionals managing people with eating disorders: a literature review. Archives Psychiatric Nursing. 2017;31(1):125-36.

13. Evans EJ, Hay PJ, Mond J, Paxton SJ, Quirk F, Rodgers B, Jhajj AK, Sawoniewska MA. Barriers to help-seeking in young women with eating disorders: a qualitative exploration in a longitudinal community survey. Eat Disord. 2011;19(3):270-85.

14. Conti J, Calder J, Cibralic S, Rhodes P, Meade T, Hewson D. 'Somebody Else's roadmap': lived experience of Maudsley and family-based therapy for adolescent anorexia nervosa. Aust NZ J Family Therapy. 2017;38(3):405-29.

15. Wonderlich S, Mitchell JE, Crosby RD, Myers TC, Kadlec K, LaHaise K, SwanKremeier L, Dokken J, Lange M, Dinkel J, Jorgensen M. Minimizing and treating chronicity in the eating disorders: a clinical overview. Int J Eat Disord. 2012;45(4):467-75.

16. Insel T, Cuthbert B, Garvey M, Heinssen R, Pine DS, Quinn K, Sanislow C, Wang $P$. Research domain criteria (RDoC): toward a new classification framework for research on mental disorders. Am J Psychiatry. 2010;167(7):748-51.

Ready to submit your research? Choose BMC and benefit from:

- fast, convenient online submission

- thorough peer review by experienced researchers in your field

- rapid publication on acceptance

- support for research data, including large and complex data types

- gold Open Access which fosters wider collaboration and increased citations

- maximum visibility for your research: over $100 \mathrm{M}$ website views per year

At BMC, research is always in progress.

Learn more biomedcentral.com/submissions 